\title{
Antipsychotic prescribing for vulnerable populations: a clinical audit at an acute Australian mental health unit at two-time points
}

Sara S McMillan ${ }^{1 *}$, Sara Jacobs², Louise Wilson², Theo Theodoros ${ }^{3,4,5}$, Gail Robinson ${ }^{1,3,6}$, Claire Anderson², Gabor Mihala ${ }^{1}$ and Amanda J Wheeler ${ }^{1,7}$

\begin{abstract}
Background: Antipsychotics are recognised as a critical intervention for schizophrenia and bipolar disorder. Guidelines globally endorse the routine practice of antipsychotic monotherapy, at the minimum effective dose. Even in treatmentresistant schizophrenia, clozapine use is endorsed before combining antipsychotics.

This aim of this study was to review antipsychotic polytherapy alone, high-dose therapy alone, polytherapy and highdose prescribing patterns in adults discharged from an inpatient mental health unit at two time-points, and the alignment of this prescribing with clinical guideline recommendations. Additionally, associations with polytherapy and high-dose antipsychotic prescribing, including patient and clinical characteristics, were explored.

Methods: A retrospective clinical audit of 400 adults (200 patients at two different time-points) discharged with at least one antipsychotic. Preliminary findings and education sessions were provided to physicians between Cohorts. Outcomes (polytherapy alone, high-dose therapy alone, polytherapy and high-dose therapy) were compared between study Cohorts using chi-squared and rank-sum tests. Associations between outcomes and covariates were assessed using multivariable logistic regression.

Results: Most patients (62.5\%) were discharged on a single antipsychotic within the recommended dose range. There was a clear preference for prescribing second generation antipsychotics, and in this respect, prescribing is aligned with current evidence-based guidelines. However, sub-optimal prescribing practices were identified for both Cohorts in relation to polytherapy and high-dose antipsychotic rates. Involuntary treatment, frequent hospitalisations and previous clozapine use significantly increased the risk of all three prescribing outcomes at discharge.

Conclusions: In a significant minority, antipsychotic prescribing did not align with clinical guidelines despite increased training, indicating that the education program alone was ineffective at positively influencing antipsychotic prescribing practices. Further consideration should be given when prescribing antipsychotics for involuntary patients, people with frequent hospitalisations, and those who have previously trialled clozapine.
\end{abstract}

Keywords: Audit, Antipsychotics, Mental IIIness

* Correspondence: s.mcmillan@griffith.edu.au

${ }^{1}$ Menzies Health Insitute, Griffith University, Brisbane, Australia

Full list of author information is available at the end of the article 


\section{Background}

Optimal management of serious mental illnesses, such as schizophrenia, bipolar affective disorder and other psychotic disorders, focuses on both symptom and functional recovery with a range of pharmacological, psychosocial and psychological interventions. Antipsychotic medication is widely recognised as a critical intervention in both acute and ongoing treatment of schizophrenia $[1,2]$, and more recently in bipolar disorder [3, 4].

Clinical practice guidelines globally endorse the routine practice of monotherapy with antipsychotic medication, at the minimum effective dose, for people with schizophrenia or bipolar disorder [1, 2, 4, 5]. Even in treatment-resistant schizophrenia, i.e. treatment failure with two different antipsychotic agents, clozapine use is endorsed before combining antipsychotic therapies $[1,2,5,6]$. The use of more than one antipsychotic is only recommended for short periods when switching treatments [7], or for people with treatment-resistant schizophrenia who have had only a partial response to clozapine [1]. Other plausible reasons include: if a person refuses to take clozapine, or there is a contraindication or intolerability to clozapine as it is associated with a significant side effect profile [8]. Reasons for clozapine ineffectiveness must be explored before adding a second antipsychotic, e.g. consumer engagement with clozapine therapy (i.e. adherence) and other medication use [1]. In their review of treatment-resistant schizophrenia, Dold and Leucht confirmed the continuing uncertainty as to which antipsychotic to recommend if clozapine is inappropriate [9]. Current Australian guidelines outline two choices: i) augmentation with another antipsychotic or electroconvulsive therapy, or ii) switch to another agent [2].

In spite of the above recommendations, antipsychotic polytherapy, or high-dose antipsychotic prescribing, or both, appears to be common practice [10-12]. Between 1970 and 2009, the globally pooled median antipsychotic polytherapy rate was $19.6 \%$ [13]. The 2010 Australian National Survey of Psychosis identified that 28\% $(n=240)$ of participants with schizophrenia were taking two or more antipsychotics [14]. There are significant concerns with antipsychotic polytherapy and dosing above therapeutic recommendations. These include, but are not limited to, lack of evidence to support efficacy [15], reduced medication adherence, drug interactions, increased treatment burden, e.g. financial costs and adverse effects, and mortality $[7,16]$.

Variables suggested to be associated with antipsychotic polytherapy include residual psychotic symptoms [17], being treated involuntarily [18], psychiatrists prescribing beliefs and clinical experience [19], and hospitalisation or longer hospital stays, which may be influenced by duration of illness [20-23]. One of the strongest predictors of high antipsychotic doses is the prescribing of more than one antipsychotic concurrently [23-26]. Overall, there is conflicting evidence for associations between patient characteristics and either antipsychotic polytherapy or highdosing, such as age [18, 23, 27, 28] and ethnicity [27-31]. For instance males have been reported to be at greater risk, or have higher rates of these outcomes [18, 23, 27, 29], yet this was not demonstrated in New Zealand [28].

Audit and feedback (clinical audit) is an intervention commonly undertaken by organisations to monitor and improve the quality of health care. A clinical audit 'compares actual practice with an optimal standard of practice' [32]; this is integral for evaluating and improving practices and ultimately, patient safety and care. It is a cycle that follows a systematic process of establishing best practice, evaluating care against explicit criteria, implementing steps to improve care, and monitoring for continual improvement [33, 34]. The aim of this paper is to review polytherapy and high-dose antipsychotic prescribing patterns in adults discharged from an inpatient mental health unit at two time-points, and the alignment of this prescribing with clinical guideline recommendations. Additionally, this paper explores associations with polytherapy and high-dose antipsychotic prescribing, including patient and clinical characteristics.

\section{Methods}

This study was a single-centre, retrospective clinical audit of 400 adults discharged with a prescription for at least one antipsychotic medication from a Queensland-based metropolitan public hospital. The hospital is the largest of three adult psychiatric hospitals in the region covering a catchment area of approximately one million people. The hospital functions as a major teaching hospital, and has 67 adult psychiatric inpatient beds, which treats both voluntary and involuntary patients admitted under the relevant legislation [35]. The catchment area also encompasses a large culturally and linguistically diverse population.

Information was obtained for 200 patients at two different time-points: patients discharged on or before the 31st January 2014 (Cohort 1), and on or before the 31st January 2015 (Cohort 2). This sample size was deemed large enough to provide adequate statistical power and an accurate reflection of hospital prescribing practices.

The time points were chosen to allow for education interventions to be provided at the start of a new trainee year, with trainees beginning their first term of 2014 at the start of February. Rotations for training psychiatry registrars through the Royal Australian and New Zealand College of Psychiatrists (RANZCP) are generally 6 months' duration for full-time trainees [36]. It was anticipated that education interventions would occur over a period of 5-10 months. It was acknowledged that the majority of education interventions were targeted towards training psychiatrists. This was done in a 
purposeful manner with training psychiatrists noted to generally have greater contact with patients and more frequent review of psychotropic medication prescription (under the guidance of supervising psychiatrists).

At the time of study (between Cohorts), the hospital ran a regular education program on Monday afternoons, for mental health medical staff (psychiatrists and training psychiatrists). Antipsychotic education was included during these sessions in a number of ways such as: a one-hour presentation by a pharmacy student highlighting the issues from a preliminary analysis of Cohort 1 findings; a onehour presentation that was video-conferenced to three hospital sites across the district presented by a training psychiatrist which specifically addressed high-dose antipsychotic prescribing and antipsychotic polypharmacy. In addition, four pharmacology sessions were provided to psychiatric trainees discussing the rational and appropriate use of psychotropic medications. These teaching sessions were conducted from February to October 2014. Pharmacology teaching to training psychiatrists was positively received, whilst education sessions on antipsychotic polypharmacy and high-dose antipsychotic use presented to consultant psychiatrists and training psychiatrists were met with a variety of responses, including defence of antipsychotic polypharmacy despite a lack of supporting evidence. Hospital mental health pharmacists were also invited to attend these education sessions, and a dedicated presentation of findings from Cohort 1 was presented to the greater hospital pharmacy group.

Ethical approval was obtained from both a University (HSV/04/15/HREC) and District Health Board (EC00167) Ethics Committee. The records for the most recent 200 adult patients discharged prior to each of the two timepoints with at least one antipsychotic prescribed, irrespective of diagnosis, were obtained (Cohort 1: January 31, 2014 to November 27, 2013; Cohort 2: January 31, 2015 to December 2, 2014). Patients were excluded if they were transferred to another ward, unit or hospital, became 'absent without permission' during their inpatient admission, or died during the admission (82 and 73 patients were excluded from each cohort respectively). For patients with multiple hospital discharges, only the most recent discharge in each Cohort was included (i.e. the one closest to the 31st January for each time-point). Nineteen patients were common to both cohorts. There were no significant changes made to the service delivery model between the two review periods.

Three electronic databases were used, by two psychiatry registrars (Cohort 1) and two Master of Pharmacy students (Cohort 2) to obtain study data (Fig. 1). Information was de-identified with a unique identifier used for study data entry in Microsoft Excel. A briefing session and procedure guide ensured that all researchers followed a standardised data collection process. A postdata entry meeting was held to combine data from the two Cohorts, and to identify and resolve any discrepancies. The following definitions were used for data collection and analysis by the researchers:

- Antipsychotic polytherapy: prescribing of two or more different antipsychotic agents simultaneously, or prescribing two or more different formulations of the same antipsychotic medication, including 'when required;'

- High-dose prescribing (total antipsychotic equivalent dose): The sum of the total daily dose (TDD) of each antipsychotic used by a patient within $24 \mathrm{~h}$ divided by the recommended maximum daily dose $[37,38]$. A total equivalent dose greater than one was classified as a high-dose;

- Ethnicity: country of birth; and,

- Involuntary treatment: included both an Involuntary Treatment Order (ITO) and a Forensic Order (FO). An ITO is endorsed by a psychiatrist and authorises a person to receive mental health treatment without consent. Alternatively, an FO is endorsed by the legal system [35].

\section{Analysis}

Data was imported into Stata 14.1 for cleaning and analysis. Results were presented as frequencies (n) and proportions (\%) for categorical data, or median and 25th/75th percentiles for continuous non-symmetrical data. Baseline characteristics were compared between cohorts using chi-

\begin{tabular}{|c|c|c|c|c|}
\hline $\begin{array}{l}\text { Patient Cohort } \\
\text { Collection (HBCIS) }\end{array}$ & $\begin{array}{l}\text { Patient } \\
\text { Demographics } \\
\text { (CIMHA) }\end{array}$ & $\begin{array}{l}\text { Clinical Data } \\
\text { (CIMHA) }\end{array}$ & $\begin{array}{l}\text { Discharge Summary } \\
\text { (CIMHA) }\end{array}$ & $\begin{array}{l}\text { Discharge } \\
\text { Medication Record } \\
\text { (eLMS) }\end{array}$ \\
\hline $\begin{array}{l}\text { - Name } \\
\text { - Record number } \\
\text { - Admission date } \\
\text { - Discharge date }\end{array}$ & $\begin{array}{l}\text { - Gender } \\
\text { - Age } \\
\text { - Ethnicity }\end{array}$ & $\begin{array}{l}\text { - Number of previous } \\
\text { mental health } \\
\text { admissions } \\
\text { - Diagnosis } \\
\text { - ECG/metabolic } \\
\text { monitoring }\end{array}$ & $\begin{array}{l}\text { - Patient consent } \\
\text { - Mental Health Act } \\
\text { status } \\
\text { - Follow up plans } \\
\text { - Clozapine trial } \\
\text { - Electroconvulsive } \\
\text { treatment }\end{array}$ & $\begin{array}{l}\text { - Antipsychotic name } \\
\text { - Form } \\
\text { - Dose } \\
\text { - Other medication } \\
\text { - Adverse drug } \\
\text { reactions }\end{array}$ \\
\hline \multicolumn{5}{|c|}{$\begin{array}{l}\text { HBCIS: Hospital Based Corporate Information System; CIMHA: Consumer Integrated Mental Health Application; eLMS: Enterprise } \\
\text { Liaison Medication System }\end{array}$} \\
\hline \multicolumn{5}{|c|}{ Fig. 1 Data collection process } \\
\hline
\end{tabular}


squared and rank-sum tests. Associations between therapy received (polytherapy alone, high-dose therapy alone, poly- and high-dose therapies) and cohort and other covariates were assessed with odds ratios, which were calculated using multivariable logistic regression. Correlations between covariates were checked using linear regression or by calculating pairwise correlation coefficients (all absolute values $r<0.40$ ). Three separate multivariable models (dependent variable: therapy received) were built using covariates presented in Table 4 including cohort. The models were derived through manual backwards step-wise removal of covariates at $p \geq 0.05$ level. Statistical significance was declared at $p<0.05$. Only significant odds ratios were presented. Missing values were not imputed. No adjustment was made for multiple comparisons.

\section{Results}

Overall, the majority of discharged patients in both Cohorts were male, with a similar median age (38 years, Cohort 1; 35 years Cohort 2; Table 1). Over three-quarters of Cohort $1(n=152 ; 76.0 \%)$ and twothirds of Cohort $2(n=137 ; 68.0 \%)$ participants were
Australian born. Similar proportions were identified between the two Cohorts with respect to primary diagnosis; the most prominent condition overall in the study population was schizophrenia $(n=148$; $37.0 \%)$. The only significant difference identified between Cohorts was the higher rate of comorbid substance use recorded for Cohort $1(p=0.001)$.

Prescribing practices across the two Cohorts were similar in terms of the antipsychotic medication used (Table 2). Second generation antipsychotics (SGA) were the most commonly prescribed antipsychotics, in particular risperidone was the most commonly prescribed agent (oral (PO) and long-acting injection (LAI), $n=125$ ), followed by olanzapine (PO and LAI, $n=123$ ), quetiapine (PO only, $n=85)$ and paliperidone (PO and LAI, $n=64)$.

Table 3 shows that the majority of patients $(n=250$ / 400; 62.5\%) were discharged on a single antipsychotic medication with a dose within the therapeutic recommendations, i.e. below the maximum recommended dose $(n=132 / 200,66.0 \%$ Cohort $1 ; n=118 / 200,59.0 \%$ Cohort 2). Overall antipsychotic polytherapy as a prescribing outcome at discharge (either alone or with

Table 1 Participant characteristics by Cohorts $(n=400)$

\begin{tabular}{|c|c|c|c|c|}
\hline & $\begin{array}{l}\text { Cohort } 1 \\
n=200\end{array}$ & $\begin{array}{l}\text { Cohort } 2 \\
n=200\end{array}$ & $\begin{array}{l}\text { Total } \\
n=400\end{array}$ & $p$-value \\
\hline Group size & $200(50 \%)$ & $200(50 \%)$ & $400(100 \%)$ & \\
\hline Gender (male) & $117(58 \%)$ & $119(60 \%)$ & $236(59 \%)$ & 0.839 \\
\hline Age (years) ${ }^{a}$ & $38(28-48)$ & $35(28-44)$ & $36(28-46)$ & $0.059^{b}$ \\
\hline \multicolumn{5}{|l|}{ Ethnicity } \\
\hline - Australian & $152(76 \%)$ & $137(68 \%)$ & $289(72 \%)$ & \multirow[t]{4}{*}{0.056} \\
\hline - Asian & $20(10 \%)$ & $14(7 \%)$ & $34(8 \%)$ & \\
\hline - Pacific Islander & $13(6 \%)$ & $23(12 \%)$ & $36(9 \%)$ & \\
\hline - Other & $15(8 \%)$ & $26(13 \%)$ & $41(10 \%)$ & \\
\hline \multicolumn{5}{|l|}{ Admissions (last 12 months) } \\
\hline - One or two & 157 (78\%) & $165(82 \%)$ & $322(80 \%)$ & \multirow[t]{3}{*}{0.582} \\
\hline - Three or four & $27(14 \%)$ & $21(10 \%)$ & $48(12 \%)$ & \\
\hline - Five or more & $16(8 \%)$ & $14(7 \%)$ & $30(8 \%)$ & \\
\hline Hospital duration (days) ${ }^{a}$ & $8(4-17)$ & $10(5-22)$ & $9(5-19)$ & $0.317^{c}$ \\
\hline \multicolumn{5}{|l|}{ Primary diagnosis } \\
\hline - Schizophrenia & $72(36 \%)$ & $76(38 \%)$ & $148(37 \%)$ & \multirow[t]{4}{*}{0.946} \\
\hline - Bipolar disorder & $27(14 \%)$ & $26(13 \%)$ & $53(13 \%)$ & \\
\hline - Other psychotic disorder & $30(15 \%)$ & $32(16 \%)$ & $62(16 \%)$ & \\
\hline - Other & $71(36 \%)$ & $66(33 \%)$ & 137 (34\%) & \\
\hline Comorbid substance use disorder & $77(38 \%)$ & $46(23 \%)$ & $123(31 \%)$ & 0.001 \\
\hline Involuntary treatment & 77 (38\%) & $84(42 \%)$ & $161(40 \%)$ & 0.475 \\
\hline Previous clozapine trial & $23(12 \%)$ & $20(10 \%)$ & $43(11 \%)$ & 0.628 \\
\hline
\end{tabular}

$\mathrm{n}(\%)$ shown unless otherwise noted

${ }^{a}$ median and inter-quartile range (25th and 75th percentiles) shown; $p$-values calculated with chi-squared test unless otherwise noted

bilcoxon rank-sum test

cmedian test 
Table 2 Antipsychotics prescribed on discharge

\begin{tabular}{|c|c|c|c|c|c|c|c|}
\hline \multirow{2}{*}{$\frac{\text { Class }}{\text { SGA }}$} & \multirow[t]{2}{*}{ Route } & \multicolumn{2}{|c|}{ First AP } & \multicolumn{2}{|c|}{ Second AP } & \multicolumn{2}{|c|}{ Third AP } \\
\hline & & $\mathrm{C} 1$ & $C 2$ & $\mathrm{C} 1$ & $\mathrm{C} 2$ & C1 & $\mathrm{C} 2$ \\
\hline Amisulpride & $\mathrm{PO}$ & 2 & 5 & 2 & 5 & & \\
\hline \multirow[t]{2}{*}{ Aripiprazole } & $\mathrm{LAl}$ & & 1 & & & & \\
\hline & $\mathrm{PO}$ & 4 & 10 & 2 & 1 & & \\
\hline Asenapine & $\mathrm{PO}$ & 2 & & & 1 & & \\
\hline Clozapine & $\mathrm{PO}$ & 17 & 13 & & 2 & & \\
\hline \multirow[t]{2}{*}{ Olanzapine } & $\mathrm{LAl}$ & 4 & & & 1 & & \\
\hline & $\mathrm{PO}$ & 45 & 45 & 12 & 16 & & \\
\hline \multirow[t]{2}{*}{ Paliperidone } & LAl & 18 & 34 & 3 & 7 & & \\
\hline & $\mathrm{PO}$ & & 1 & 1 & & & \\
\hline Quetiapine & $\mathrm{PO}$ & 39 & 31 & 6 & 7 & 2 & \\
\hline \multirow[t]{2}{*}{ Rispiridone } & $\mathrm{LAl}$ & 13 & 6 & 5 & 4 & & \\
\hline & $\mathrm{PO}$ & 34 & 38 & 11 & 14 & & \\
\hline Ziprasidone & $\mathrm{PO}$ & 3 & 1 & & & & \\
\hline \multirow[t]{2}{*}{ Subtotal } & $\mathrm{IM}$ & 35 & 41 & 8 & 12 & & \\
\hline & $\mathrm{PO}$ & 146 & 144 & 34 & 46 & 2 & \\
\hline FGA & & $\mathrm{C} 1$ & $\mathrm{C} 2$ & $\mathrm{C} 1$ & C2 & $\mathrm{C} 1$ & $\mathrm{C} 2$ \\
\hline Chlorpromazine & $\mathrm{PO}$ & 2 & 2 & 1 & 3 & 2 & \\
\hline Flupenthixol & $\mathrm{LAl}$ & 2 & 2 & 3 & 3 & & \\
\hline Fluphenazine & $\mathrm{LAl}$ & & & & 2 & & \\
\hline \multirow[t]{2}{*}{ Haloperidol } & $\mathrm{LAl}$ & 2 & & 1 & & & \\
\hline & $\mathrm{PO}$ & 2 & 1 & 1 & 1 & & \\
\hline \multirow[t]{2}{*}{ Zuclopenthixol } & $\mathrm{LAl}$ & 11 & 10 & 5 & 6 & & \\
\hline & $\mathrm{PO}$ & & & 2 & 1 & & \\
\hline \multirow[t]{2}{*}{ Subtotal } & $\mathrm{IM}$ & 15 & 12 & 9 & 11 & & \\
\hline & $\mathrm{PO}$ & 4 & 3 & 4 & 5 & 2 & \\
\hline \multirow[t]{2}{*}{ AP Total } & $\mathrm{IM}$ & 50 & 53 & 17 & 23 & & \\
\hline & $\mathrm{PO}$ & 150 & 147 & 38 & 51 & 4 & \\
\hline TOTAL & & 200 & 200 & 55 & 74 & 4 & \\
\hline
\end{tabular}

SGA Second generation antipsychotic, FGA First generation antipsychotic, $P O$ oral; LAI Long-acting injection, AP Antipsychotic, C1 Cohort 1, C2 Cohort 2

high-dose antipsychotic therapy) was found in just less than a third ( $n=130 / 400 ; 32.5 \%)$ of the study population ( $n=56,28.0 \%$ Cohort $1 ; n=74,37.0 \%$ Cohort 2). Overall high-dose antipsychotic therapy as a prescribing outcome at discharge (either alone or with antipsychotic

Table 3 Therapy received by cohort

\begin{tabular}{llllll}
\hline \multicolumn{2}{l}{ Therapy received } & & \multicolumn{2}{l}{ Frequency } \\
\cline { 5 - 6 } \cline { 5 - 6 } Polytherapy & High dose & & $\begin{array}{l}\text { Cohort 1 } \\
n=200\end{array}$ & $\begin{array}{l}\text { Cohort 2 } \\
n=200\end{array}$ & $\begin{array}{l}\text { Total } \\
N=400\end{array}$ \\
\hline No & no & 132 & 118 & 250 \\
Yes & no & 32 & 36 & 68 \\
No & yes & 12 & 8 & 20 \\
Yes & yes & 24 & 38 & 62 \\
\hline
\end{tabular}

polytherapy) was found in $20.5 \%(n=82 / 400)$ of the study population ( $n=36 / 200,18.0 \%$ Cohort $1 ; n=46 /$ 200, 23.0\% Cohort 2). A total of 62 patients (15.5\%) were prescribed both antipsychotic polytherapy and high-dose therapy at discharge $(n=24 / 200,12.0 \%$ Cohort 1 ; $n=38 / 200,19.0 \%$ Cohort 2).

\section{Associations with polytherapy and high-dose antipsychotic prescribing}

Associations between three antipsychotic prescribing outcomes at discharge: (i) polytherapy only; (ii) high-dose therapy only; and (iii) polytherapy and high-dose therapy together were investigated in a regression model with the following variables: Cohort, participant demographics, hospital admissions in the last 12 months, primary diagnosis, comorbid substance use disorder, involuntary treatment status and previous clozapine trial (Table 4).

There was a difference between Cohorts with respect to two outcomes: (i) polytherapy alone, and (iii) polytherapy and high-dose together; patients in Cohort 2 were 1.8 times more likely to be discharged on polytherapy alone and more than twice as likely to be discharged on polytherapy and high-dose therapy together. No significant associations were identified between the three outcomes and patients' age, gender, ethnicity, and having a comorbid substance use disorder.

Those patients who had five or more admissions in the previous 12 months were significantly more likely to be discharged on (i) antipsychotic poytherapy alone and (iii) polytherapy and high-dose therapy together; the risk of polytherapy alone at discharge was 7.5 times more likely and polytherapy and high-dose therapy together was 5.3 times more likely compared to those patients admitted less frequently.

Compared to patients with schizophrenia, those with all other diagnoses were significantly less likely to be prescribed polytherapy alone. The likelihood of antipsychotic polytherapy plus high-dose therapy was similar between patients diagnosed with schizophrenia and those with other psychotic disorders, but was significantly lower for those with bipolar and other disorders.

Involuntary treatment and previous clozapine use significantly increased the risk of all three prescribing outcomes at discharge (Table 4).

\section{Discussion}

Overall, this study found that the majority of patients $(62.5 \%)$ were discharged on a single antipsychotic within the recommended dose range. There was a clear preference for prescribing SGAs, which are recommended firstline agents for schizophrenia and schizoaffective disorder by the RANZCP [2]. In this respect, prescribing is aligned with current evidence-based guidelines. However, suboptimal prescribing practices were identified for both 
Table 4 Multivariable logistic regressions (associations between therapy received and cohort/other covariates)

\begin{tabular}{|c|c|c|c|}
\hline \multirow[b]{2}{*}{ Therapy received } & \multicolumn{3}{|c|}{ Adjusted odds ratio $(95 \% \mathrm{Cl})$ of therapy received } \\
\hline & Polytherapy & High dose & Polytherapy and high dose \\
\hline Model size & $n=400$ & $n=400$ & $n=312$ \\
\hline Cohort (base: 1st) & $1.81(1.08-3.02)^{*}$ & - & $2.14(1.10-4.17)^{*}$ \\
\hline Gender (base: male) & - & - & - \\
\hline Age (year) & - & - & - \\
\hline Ethnicity (base: Australian) & - & - & - \\
\hline \multicolumn{4}{|l|}{ Adm. in last 12 m (base: one or two): } \\
\hline - three or four & $1.77(0.87-3.60)$ & - & $2.28(0.97-5.35)$ \\
\hline - five or more & $7.52(2.92-19.4)^{*}$ & - & $5.30(1.57-17.8)^{*}$ \\
\hline Hospital stay (day) & $\wedge$ & $\wedge$ & $\wedge$ \\
\hline \multicolumn{4}{|l|}{ Primary diagn. (base: schizophrenia): } \\
\hline - bipolar disorder & $0.19(0.08-0.47)^{*}$ & - & $0.26(0.08-0.80)^{*}$ \\
\hline - other psychotic disorder & $0.33(0.14-0.75)^{*}$ & - & $0.33(0.11-1.00)$ \\
\hline - other & $0.40(0.21-0.76)^{*}$ & - & $0.40(0.17-0.91)^{*}$ \\
\hline Comorbid substance use disorder & - & - & - \\
\hline Involuntary treatment & $3.95(2.31-6.77)^{*}$ & $2.22(1.34-3.66)^{*}$ & $3.18(1.61-6.29)^{*}$ \\
\hline Previous clozapine trial & $5.80(2.43-13.8)^{*}$ & $2.19(1.10-4.38)^{*}$ & $5.58(2.04-15.3)^{*}$ \\
\hline
\end{tabular}

$\mathrm{Cl}$ confidence interval, * $p<0.05$; hyphen $=$ excluded from multivariable model at $p \geq 0.50 ; \wedge=$ excluded due to multicorreality; $m$ months, diagn. diagnosis, adm. admissions

Cohorts in relation to polytherapy and high-dose antipsychotic rates. Subsequently, a number of patients were at risk of adverse consequences as a result of their discharge treatment. This was despite increased clinician education prior to the second time-point (Cohort 2), reflecting the need for a review of the training provided at a local level and in wider medical education. Our audit results provide further evidence that gender, age and ethnicity are not associated with polytherapy or high dose $[26,28]$, although the ethnic minority groups made up only about $30 \%$ of each Cohort. Patients with a primary diagnosis of schizophrenia were identified to be at significantly greater risk of polytherapy alone or polytherapy and high dose antipsychotic use. Lastly, polytherapy alone, high antipsychotic dose alone, and polytherapy/high-dose therapy combined were significantly associated with the following three consumer variables: five or more previous hospital admissions within the last 12 months, involuntary treatment and previous clozapine use.

These results should be considered with respect to other recent research in this area. A similar audit was conducted with 272 inpatients in Portugal in 2012 [39]. Compared to our study, Campose-Mendes et al. identified a higher proportion of patients on polytherapy, as well as those on high dose therapy [39]; this may be expected with an audit undertaken in 12 psychiatric units compared to our one. Involuntary treatment and prior psychiatric admission was found to be associated with high dose in both studies [39]. Our study did not explore associations depending on the formulation of the antipsychotic or employment status.

The frequency of antipsychotic polytherapy alone was similar between the two Cohorts, and it was encouraging to see that the majority of patients were being treated with one antipsychotic. The total rates of any antipsychotic polytherapy in this study were lower than those reported in a small Australian audit of hospital inpatients with schizophrenia [40]; Malhi et al. did not investigate associated high-dose antipsychotic prescribing.

While our relatively low rate of antipsychotic polytherapy alone could be viewed positively, this needs to be considered in association with high dosing or whether clozapine has been trialled. A similar proportion of patients were discharged with polytherapy and high-dose therapy, particularly those patients in Cohort 2. An investigation into what drives this outcome is needed in this clinical setting; was a second (or third) antipsychotic agent added after an increased dose or vice versa? As polytherapy and high antipsychotic dosing escalates the risk of adverse effects, which can lead to rehospitalisation, the consequences of, and lack of supportive evidence for such a combination, must be reiterated to clinicians. This audit emphasises the need to develop further strategies to reduce these rates in this particular hospital. However, it is noted that the audit specifically gathered clinical information from discharge summaries and pharmacy software at a cross-sectional time-point. With a high acuity of psychiatric illness in 
the inpatient psychiatric unit, and increasing referrals, there are increased pressures for access to inpatient psychiatric beds and reduced length of stay. It is therefore plausible that patients may be discharged on antipsychotic polypharmacy with a plan to reduce and cease this following discharge.

Clozapine use is the most effective medication for treatment-resistant schizophrenia [41], and would circumvent the need for antipsychotic polytherapy for many patients. Only $11 \%(n=43)$ of the total number of patients in this audit were trialled on clozapine. This low number may have been influenced by psychiatrist prescribing experiences and beliefs, underscoring the predisposition for clinicians to delay prescribing clozapine for patients with treatment-resistant schizophrenia [28]. This tendency is believed to be influenced by a range of factors, including but not limited to, clozapine's serious adverse effect profile [42], and the perception that consumers are less satisfied with this treatment choice [43]. While this practice appears to be improving internationally [44] and in Australia [41], further investigation is needed as to the reasons for low clozapine prescribing rates in this particular hospital setting. What is known is that the increased education between Cohorts did not specifically focus on the indications and utility of clozapine. Furthermore, by sourcing clinical data from discharge summaries which are supposedly designed to be the primary clinical communication tool on discharge and transfer of care, these may not always be comprehensively authored and may therefore omit information in regards to prior clozapine trials. An underestimation of the rate of patients previously trialled on clozapine is therefore possible. It should be noted that for those patients with a previous clozapine trial, there was a greater likelihood of being prescribed antipsychotic polytherapy or polytherapy and/or high-dose. The reasons behind treatment failure with clozapine were unable to be explored in this study, but underscore the difficulty in treating patients with treatment-resistant schizophrenia especially when clozapine treatment has been stopped.

Patients diagnosed with schizophrenia in our study were also more likely to be prescribed antipsychotic polytherapy alone or with high-dose compared to those with bipolar disorder or other mental illness. The association with polytherapy alone is supported by a US based audit of outpatients visiting office-based psychiatrists [11]; other inpatient studies did not explore such associations [45], or focused solely on patients with a diagnosis of schizophrenia or related disorder [22, 24, 25]. Antipsychotics are often not first-line treatment for other mental illnesses, such as bipolar disorder. Thus, the significant relationship found between diagnosis and antipsychotic polytherapy was to some extent expected given that the majority of patients in both Cohorts had a primary diagnosis of schizophrenia.
Involuntary treatment was found to be significantly associated with antipsychotic polytherapy, with increased rates or similar associations seen in other countries [18, 46]. These vulnerable patients were also more likely to be prescribed high dose, or both polytherapy and high dose antipsychotics. Similarly, other research has confirmed that compulsory detention/involuntary patients are at a greater risk of being prescribed high antipsychotic doses [18, 24, 47, 48].

People hospitalised more than five times in the previous year were significantly more likely to be prescribed more than one antipsychotic. These consumers would have been clinically unstable; multiple antipsychotics are likely to have been prescribed as an attempt to stabilise the patient. This result underscores the need for clinicians to take particular care and attention towards both of the above vulnerable patient groups, and the reasons for such high hospitalisation rates, e.g. side effects, nonadherence, ineffective treatment, etc. must be investigated. In particular, the role of shared-decision making can be particularly important in this context; a qualitative study exploring this concept with mental health pharmacists identified the view that involving patients with serious mental illnesses in treatment decisions would improve adherence and clinical outcomes [49]. It is not known to what degree, shared-decision making was utilised in this hospital setting for audit participants as this data was not specifically captured. It is however noted that person-centred care is a core value of the service. Future audits in this area should consider the inclusion of shared-decision making as an additional variable.

Fewer variables were found to be associated with any high antipsychotic dosing compared to antipsychotic polytherapy. Of concern, however, is that overall $20 \%$ of patients were prescribed a high antipsychotic dose, placing these patients at a higher risk of adverse effects. While there are variable definitions of 'high dose', the prevalence of solely high-dose prescribing in this audit was higher than that of discharged patients from a UK psychiatric ward (6.8\%) [50] and Hong Kong inpatients (9.2\%) [47].

An escalation protocol for identification of prescribing practices considered potentially dangerous and the need for out-of-study follow-up by an independent senior psychiatrist was included in our research design for ethics approval. In the event, no patients were identified to require use of this escalation pathway.

\section{Future research and practice recommendations}

The observed sub-optimal antipsychotic prescribing practices at discharge from this hospital demonstrates a need for future improvement. Prescribers (training psychiatry registrars and consultant psychiatrists) need to explain the justification for treatment choices in key 
handover documentation such as discharge summaries. Despite the RANZCP Clinical Practice Guidelines for the Management of Schizophrenia being eight to 10 years old over the time-periods that the audit was conducted, there were deviations from recommended practice. Additionally, there remains a recommendation in the literature for antipsychotic monotherapy and the use of clozapine.

The preliminary results of the audit have influenced the service to develop a dedicated committee to explore and develop treatment pathways for psychosis. Through this committee, draft guidelines on the treatment of psychosis which further address aspects of care discussed in the audit such as antipsychotic polypharmacy, high dose antipsychotic prescription, the use of clozapine, and further augmentation strategies in treatmentresistant psychosis have been developed. These locally specific guidelines are based on current evidence and indicate a requirement to obtain consultant psychiatrist approval for high dose antipsychotic and antipsychotic polypharmacy prescription, and emphasise the need to clearly document and justify individual patient treatment decisions. The draft version of the treatment pathway for psychosis guidelines has been distributed to all training psychiatry registrars and consultant psychiatrists across the service for comment. Following finalisation of these guidelines, implementation, and a period of practice, it would be useful to analyse a third Cohort of patients to determine if there is a subsequent beneficial change to prescribing practices.

Inclusion and review of all psychotropic medications may provide a better understanding of clinical decisionmaking and the extent of psychotropic polypharmacy as a whole and thus total medication burden experienced by patients. Furthermore, many cases of polytherapy in our study involved combinations of oral and LAI antipsychotics; rationale for this combination regimen were not explored. Whilst this practice is not uncommon $[51,52]$, there is little evidence to support this practice, especially if the LAI antipsychotic was introduced to manage adherence problems with an oral medication. This is worthy of further exploration to identify patients at risk of poor treatment outcomes [51].

An aspect of psychiatric care not explored in the audit was the utilisation of pharmacists with specialist mental health expertise. This audit and the pool of literature referenced highlight the considerable variability in regards to psychiatric treatments, and the potential for negative impacts on morbidity and mortality. A future area of research may seek to compare prescribing practices in psychiatric units with dedicated mental health pharmacists and those without. If significant differences are noted, this may inform service delivery, policy creation and workforce reforms.

\section{Strengths and limitations}

Study strengths include the standardised data collection process and large sample size. With procedural guidelines followed by all researchers, and regular debriefs, this ensured that data was collected and recorded accurately and consistently. This audit contributes to the literature by providing a better understanding of antipsychotic polytherapy and high-dose prescribing, their relationship and risk factors associated with this practice. Furthermore, this study was more inclusive by involving patients with conditions beyond schizophrenia. Finally, a key strength of this study was the exploration of variables associated with polytherapy and high dose prescribing; many published studies have focused on one or the other, not both.

However, the audit results should be interpreted within its limitations. Firstly, as a retrospective study, the quality of the data was dependent on the accuracy and completeness of clinical notes. In this particular hospital setting, clinical notes varied in terms of the quantity and quality of documented information, and there was no reliable recording of adverse effects specific to antipsychotic use. It would have been useful to consider the justification for prescribing long-term polytherapy; this information was not consistently recorded by clinicians. Unlike the work by Kadra et al. [53], the definition of antipsychotic polytherapy used did not include a time-frame; it may be that some patients were on two antipsychotics temporarily due to cross-titration, or were using an oral antipsychotic for short term use whilst commencing a long acting formulation. This information could not be identified from patient records alone in this audit; hence there is a possibility that the rates of polytherapy are over-estimated for both Cohorts [51]. With regards to additional psychotropic prescribing information, limited data regarding antidepressants, mood stabilisers and benzodiazepine medications was collected, however, it was beyond the scope of the study to widen the focus primarily because of the limited timeframes of postgraduate student research. Lastly, this audit was situated in one clinical setting in Australia, limiting the generalisability to other healthcare settings beyond this context.

\section{Conclusion}

In a significant minority antipsychotic prescribing practices did not align with clinical guidelines, despite increased education for prescribers in-between Cohorts. This indicates that the education program alone and well established clinical practice guidelines (RANZCP) were ineffective at positively influencing antipsychotic prescribing practices. The subsequent approach to local guideline development is based on the premise of the importance of prescriber engagement in bringing about practice change. Overall, it appears that further consideration should be 
given when prescribing antipsychotics for involuntary patients, people with frequent hospitalisations, and those who have previously trialled clozapine. The study findings also highlight the considerable variability in psychiatric prescribing practices, and the need for further research including additional audits and evaluation of the effectiveness of formal education programs and treatment guidelines.

\section{Acknowledgements}

We would like to thank the hospital setting for their support in this research project and to the participants whose information we used to conduct this audit. The authors would also like to thank Mei Lee and Veta-Marie Peereboom for their assistance.

\section{Funding}

None.

\section{Availability of data and materia}

The data that support the findings of this study are available from the audit site but restrictions apply to the availability of these data, which is not publically available.

\section{Authors' contributions}

SM was co-supervisor of the two research students (SJ and LW) and drafted the manuscript. SJ and LW assisted with the literature review, data collection and the first analysis of the data. Tा was the principal investigator, completed ethics approval, developed the research procedural guidelines, conducted regular meetings with research participants, acted as a co-supervisor of the two research students (SJ and LW) during the data collection phase, and assisted with preparation of the manuscript. GR assisted in initial project design, ethics application preparation and clinical governance of the audit and any potential concerns raised. CA acted as a co-supervisor for SJ and LW who were undertaking a semester abroad for the University of Nottingham MPharm course. GM undertook the data analysis and contributed to the preparation of the results and contributed to drafting the manuscript. AW was involved in audit design, ethics approval, the data collection protocol, student supervision and training, data analysis and preparation of the manuscript. All authors read and approved the final manuscript.

\section{Competing interests}

Theo Theodoros is a current employee with the hospital health service at the audit site, MSAMHS (Metro South Addiction and Mental Health Service) Princess Alexandra Hospital.

\section{Consent for publication}

Not applicable.

\section{Ethics approval and consent to participate}

Ethics approval was obtained from Griffith University (HSV/04/15/HREC) and a District Health Board (EC00167) Ethics Committee.

\section{Publisher's Note}

Springer Nature remains neutral with regard to jurisdictional claims in published maps and institutional affiliations.

\footnotetext{
Author details

${ }^{1}$ Menzies Health Insitute, Griffith University, Brisbane, Australia. ${ }^{2}$ Division of Pharmacy Practice and Policy, School of Pharmacy, University of Nottingham, Nottingham, UK. ${ }^{3}$ Faculty of Medicine, University of Queensland, Brisbane, Australia. ${ }^{4}$ Royal Australia and New Zealand College of Psychiatrists Trainee, Melbourne, Victoria, Australia. ${ }^{5}$ Metro South Addiction and Mental Health Services, Department of Health, Brisbane, Queensland, Australia. ${ }^{6}$ Metro North Mental Health Services, Department of Health, Brisbane, Queensland, Australia. ${ }^{7}$ Faculty of Medical and Health Sciences, Auckland University, Auckland, New Zealand.
}

Received: 5 November 2016 Accepted: 31 March 2017

Published online: 13 April 2017

\section{References}

1. National Institute for Health and Care Excellence: Psychosis and schizophrenia in adults: prevention and management. In: NICE guidelines [CG178]. vol. 2016; 2014

2. Galletly C, Castle D, Dark F, Humberstone V, Jablensky A, Killackey E, Kulkarni J, McGorry P, Nielssen O, Tran N. Royal Australian and New Zealand College of Psychiatrists clinical practice guidelines for the management of schizophrenia and related disorders. Aust N Z J Psychiatry. 2016;50:410-72.

3. Mclntyre $R$, Katzman M. The role of atypical antipsychotics in bipolar depression and anxiety disorders. Bipolar Disord. 2003;5(Suppl 2):20-35.

4. National Institute for Health and Care Excellence: Bipolar disorder: assessment and management. In: NICE guidelines [CG185]. vol. 2016; 2014

5. Barnes TR. Evidence-based quidelines for the pharmacological treatment of schizophrenia: recommendations from the British Association for Psychopharmacology. J Psychopharmacol. 2011;25:567-620.

6. Barnes TRE, Paton C. Antipsychotic Polypharmacy in Schizophrenia: Benefits and Risks. CNS Drugs. 2011;25:383-99.

7. Lochmann van Bennekom MW, Gijsman HJ, Zitman FG. Antipsychotic polypharmacy in psychotic disorders: a critical review of neurobiology, efficacy, tolerability and cost effectiveness. J Psychopharmacol. 2013;27:327-36.

8. Mortimer AM, Singh P. Shepherd CJ, Puthiryackal J. Clozapine for treatmentresistant schizophrenia: National Institute of Clinical Excellence (NICE) guidance in the real world. Clin Schizophr Relat Psychoses. 2010;4:49-55.

9. Dold M, Leucht S. Pharmacotherapy of treatment-resistant schizophrenia: a clinical perspective. Evid Based Ment Health. 2014;17:33-7.

10. Dey S, Menkes DB, Obertova Z, Chaudhuri S, Mellsop G. Antipsychotic prescribing and its correlates in New Zealand. Australas Psychiatry. 2016;24:360-4.

11. Mojtabai R, Olfson M. National trends in psychotropic medication polypharmacy in office-based psychiatry. Arch Gen Psychiatry. 2010;67:26-36

12. Patel MX, Bishara D, Jayakumar S, Zalewska K, Shiers D, Crawford MJ, Coope SJ. Quality of prescribing for schizophrenia: Evidence from a national audit in England and Wales. Eur Neuropsychopharmacol. 2014;24:499-509.

13. Gallego JA, Bonetti J, Zhang J, Kane JM, Correll CU. Prevalence and correlates of antipsychotic polypharmacy: A systematic review and metaregression of global and regional trends from the 1970s to 2009. Schizophr Res. 2012;138:18-28.

14. Waterreus A, Morgan VA, Castle D, Galletly C, Jablensky A, Di Prinzio P, Shah S. Medication for psychosis-consumption and consequences: the second Australian national survey of psychosis. Aust N Z J Psychiatry. 2012;46:762-73

15. Davis JM, Chen N. Dose response and dose equivalence of antipsychotics. J Clin Psychopharmacol. 2004:24:192-208.

16. Fleischhacker WW, Uchida H. Critical review of antipsychotic polypharmacy in the treatment of schizophrenia. Int J Neuropsychopharmacol. 2014;17: 1083-93.

17. Grech P, Taylor D. Long-term antipsychotic polypharmacy: how does it start, why does it continue? Ther Adv Psychopharmacol. 2012;2:5-11.

18. Lelliott P, Paton C, Harrington M, Konsolaki M, Sensky T, Okocha C. The influence of patient variables on polypharmacy and combined high dose of antipsychotic drugs prescribed for in-patients. Psychol Bull. 2002;26:411-4.

19. Correll CU, Shaikh L, Gallego JA, Nachbar J, Olshanskiy V, Kishimoto T, Kane JM. Antipsychotic polypharmacy: a survey study of prescriber attitudes, knowledge and behavior. Schizophr Res. 2011;131:58-62

20. Sun F, Stock EM, Copeland LA, Zeber JE, Ahmedani BK, Morissette SB. Polypharmacy with antipsychotic drugs in patients with schizophrenia: trends in multiple health care systems. Am J Health Syst Pharm. 2014;71: 728-38.

21. Connolly A, Taylor D. Factors associated with non evidence-based prescribing of antipsychotics. Ther Adv Psychopharmacol. 2014:4:247-56.

22. John AP, Gee T, Alexander S, Ramankutty P, Dragovic M. Prevalence and nature of antipsychotic polypharmacy among inpatients with schizophrenia spectrum disorders at an Australian mental health service. Australas Psychiatry. 2014;22:546-50

23. Sim K, Su A, Fujii S, Yang SY, Chong MY, Ungvari GS, Si T, Chung EK, Tsang $H Y$, Chan YH, et al. Antipsychotic polypharmacy in patients with schizophrenia: a multicentre comparative study in East Asia. Br J Clin Pharmacol. 2004;58:178-83. 
24. Paton C, Barnes TRE, Cavanagh M-R, Taylor D, Lelliott P. High-dose and combination antipsychotic prescribing in acute adult wards in the UK: the challenges posed by p.r.n. prescribing. Br J Psychiatry. 2008;192:435-9.

25. Roh D, Chang J-G, Kim C-H, Cho H-S, An SK, Jung Y-C. Antipsychotic polypharmacy and high-dose prescription in schizophrenia: a 5-year comparison. Aust N Z J Psychiatry. 2014;48:52-60.

26. Gisev N, Bell JS, Chen TF. Factors associated with antipsychotic polypharmacy and high-dose antipsychotics among individuals receiving compulsory treatment in the community. J Clin Psychopharmacol. 2014;34:307-12.

27. dosReis S, Zito JM, Buchanan RW, Lehman AF. Antipsychotic dosing and concurrent psychotropic treatments for Medicaid-insured individuals with schizophrenia. Schizophr Bull. 2002;28:607-17.

28. Wheeler AJ. Treatment Pathway and Patterns of Clozapine Prescribing for Schizophrenia in New Zealand. Ann Pharmacother. 2008;42:852-60.

29. Arnold LM, Strakowski SM, Schwiers ML, Amicone J, Fleck DE, Corey KB, Farrow JE. Sex, ethnicity, and antipsychotic medication use in patients with psychosis. Schizophr Res. 2004;66:169-75.

30. Connolly A, Taylor D, Sparshatt A, Cornelius V. Antipsychotic prescribing in Black and White hospitalised patients. J Psychopharmacol. 2011;25:704-9.

31. Wheeler A, Humberstone V, Robinson E. Ethnic comparisons of antipsychotic use in schizophrenia. Aust N Z J Psychiatry. 2008;42:863-73.

32. Wheeler A, Humberstone V, Robinson E, Sheridan J, Joyce P. Impact of audit and feedback on antipsychotic prescribing in schizophrenia. J Eval Clin Pract. 2009;15:441-50.

33. Ministry of Health. Toward clinical excellence: an introduction to clinical audit, peer review and other clinical practice pmprovements. Wellington: Ministry of Health; 2002.

34. National Institute for Clinical Excellence. Principles for Best Practice in Clinical Audit. Oxon: Radcliffe Medical Press Ltd; 2002.

35. Queensland Government: Mental Health Act 2000. Queensland; 2000.

36. About the training program [https://www.ranzcp.org/Pre-Fellowship/2012Fellowship-Program/About-the-training-program.aspx]. Accessed 21 Oct 2016.

37. Taylor D, Paton C, Kapur S. The Maudsley Prescribing Guidelines in Psychiatry, 11 edn: UK: Wiley-Blackwell; 2012.

38. Joint Formulary Committee. British National Formulary (BNF) 69. London: BMJ Publishing Group Ltd, Royal Pharmaceutical Society; 2015.

39. Campos Mendes J, Azeredo-Lopes S, Cardoso G. Patterns of antipsychotics' prescription in Portuguese acute psychiatric wards: A cross-sectional study. Psychiatry research. 2016;246:142-8.

40. Malhi G, Adams D, Bernardi E, Miller M, Mulder R, Walter G, Smith B. Time to 'get real': preliminary insights into the long-term management of schizophrenia. Australas Psychiatry. 2010;18:115-9.

41. Forrester T, Siskind D, Winckel K, Wheeler A, Hollingworth S. Increasing Clozapine Dispensing Trends in Queensland, Australia 2004-2013. Pharmacopsychiatry. 2015;48:164-9.

42. Meltzer HY. Clozapine. Clin Schizophr Relat Psychoses. 2012;6:134-44.

43. Nielsen J, Dahm M, Lublin H, Taylor D. Psychiatrists' attitude towards and knowledge of clozapine treatment. J Psychopharmacol. 2010;24:965-71.

44. Wheeler AJ, Feetam CL, Harrison J. Pathway to clozapine use: a comparison between a patient cohort from New Zealand and a cohort from the United Kingdom. Clin Drug Investig. 2014;34:203-11.

45. Mace S, Taylor D. Reducing the rates of prescribing high-dose antipsychotics and polypharmacy on psychiatric inpatient and intensive care units: results of a 6-year quality improvement programme. Ther Adv Psychopharmacol. 2015;5:4-12.

46. Santone G, Bellantuono C, Rucci P, Picardi A, Preti A, de Girolamo G. Patient characteristics and process factors associated with antipsychotic polypharmacy in a nationwide sample of psychiatric inpatients in Italy. Pharmacoepidemiol Drug Saf. 2011;20:441-9.

47. Hung GB, Cheung HK. Predictors of high-dose antipsychotic prescription in psychiatric patients in Hong Kong. Hong Kong Med J. 2008;14:35-9.

48. Gisev N, Bell JS, Chen TF. A retrospective study of psychotropic drug use among individuals with mental illness issued a community treatment order. Int J Clin Pract. 2014;68:236-44

49. Younas M, Bradley E, Holmes N, Sud D, Maidment ID. Mental health pharmacists views on shared decision-making for antipsychotics in serious mental illness. Int J Clin Pharm. 2016:38:1191-9.

50. Tungaraza TE, Zahid U, Venkataramaiah B. Polypharmacy and high-dose antipsychotics at the time of discharge from acute psychiatric wards. B. Psych Bulletin. 2011;35:288-92.
51. Wheeler A. Explicit versus implicit review to explore combination antipsychotic prescribing. J Eval Clin Pract. 2009;15:685-91.

52. Wheeler A, Vanderpyl J, Carswell C, Stojkovic M, Robinson E. Explicit review of risperidone long-acting injection prescribing practice. J Clin Pharm Ther. 2011;36:651-63.

53. Kadra G, Stewart R, Shetty H, Jackson RG, Greenwood MA, Roberts A, Chang C-K, MacCabe JH, Hayes RD. Extracting antipsychotic polypharmacy data from electronic health records: developing and evaluating a novel process. BMC Psychiatry. 2015;15:166

\section{Submit your next manuscript to BioMed Central and we will help you at every step:}

- We accept pre-submission inquiries

- Our selector tool helps you to find the most relevant journal

- We provide round the clock customer support

- Convenient online submission

- Thorough peer review

- Inclusion in PubMed and all major indexing services

- Maximum visibility for your research

Submit your manuscript at www.biomedcentral.com/submit
Biomed Central 